\title{
Relationships between Flexible Display's Form Factors and its User Experience Types
}

\author{
Seung Eun Chung ${ }^{1}$ and Han Young Ryoo ${ }^{2, *}$ \\ ${ }^{1,2}$ Division of Digital Media, Ewha Womans University, 52, Ewhayeodae-gil, \\ Seodaemun-gu, Seoul 03760 Republic of Korea. \\ ${ }^{1}$ ilovechse@ewha.ac.kr, ${ }^{2}$ hyryoo@ewha.ac.kr \\ * Corresponding Author
}

\begin{abstract}
It is expected that the flexible display will provide various physical forms of the interface through its bendable, rollable or foldable characteristics without any damage and these forms are considered as the core factors to deliver user experiences in the interface. In this study, we determined the ways of utilization of the form factors in the design phase of the user experience by analyzing the effectiveness of the lextble display's form factors to each and every user experience type through a survey. The analyzed user experiences are Functionality, Understandability Pleasure, Convenience, Familiarity, Stimulation, Adaptability, Collectivity, Reality, and Aesthetic; the results showed that each user experience type has a different level of effectiveness of the form factors. This indicated that particular user experiences and certain form factors are related and implies that the designer can use certain form factors to express particular user experiences.
\end{abstract}

Keywords: Flexible Display, Fond Factors User Experience Design

\section{Introduction}

With a new useren ironment being introduced such as IOT, Wearable, development of the new applicable display devices is in progress with the Flexible Display as the representative result, The Flexible Display is bendable and unbreakable and according to its flexibility realization degrees, it can be classified as Curved Display, Bendable Display, Rollable Display, Foldable Display, and Stretchable Display [1].

Such flexible displays introductions facilitate several changes in design activities. Traditionally, the designers have had restrictions in terms of their role when designing flat displays, being able to design the parts alone while excluding the display device. However, bendable, foldable or rollable flexible displays have enabled the designers to create new user experiences [2]; however, the designers still have difficulties using them. New techniques or devices provide new opportunities and at the same time, barriers to the designers. Especially, lack of relevant knowledge or experience in using them, create obstacles for designers [3]. Therefore, it is an important phase to understand and experience flexible displays in various aspects. Particularly, considering bendable flexible display's characteristics, understanding the changes of the user experiences by its physical form is imperative, since it is needed to provide objective understanding of which form factors can be used when designing the flexible display interface to extract a certain experience that meets the users' expectation.

In this study, by examining the effectiveness of the user's expected experience types [4] using the suggested flexible display's form factors in the preceding research [1], form factors and their form factor values that can be used in the user experience designs are derived. 


\section{Flexible Display's Form Factors and User Experience}

The flat display provides the output results on a screen with graphic changes; whereas in contrast, flexible displays allow the user to directly input the data with multi-touch or both hands gestures and their characteristics can be defined by the interfaces that make physical form's deformation according to the output results [5]. These characteristics have led to discussion of the purpose of the form expression and deformation of the interface that carries flexible displays.

Rasmussen et al. [3] reported the interface's form changes to show different user experiences and also discussed that the changes are for functional and hedonic experiences through 44 case studies. Their studies are only sketchy assessments and limited to the workshops or exhibition cases, but they have highlighted the necessity of the conceptualization of the relationship between the interface's form types and the user experiences.

The studies about the interface that take into account the flexible display's technical characteristics appeared around 2000, and suggest different kinds of flexible display's forms, such as a desk form that is bent in 90 degrees [6], a cylindrical form that can be seen by many in public [7], a spherical form that can be seen in 360 degrees [8], a form that can be broaden by unrolling like a toilet paper [9], a form that can be folded in many different ways like a piece of paper [10], and a more conplicated form like an umbrella or a folding fan [11]. A form, in terms of design, is a comprehensive concept of a structure that composes the whole and is composed of form factors that can be exclusively classified by physical characteristics. Thus an analyticat approach is required by classifying the values of the form factor's quantity or quality (or specific criteria) that change the physical forms [12].

Design studies regarding the relationship between the form and the user experience provide a more detailed discussion on the exanples of attempts to measure the user experiences by the form factor values. These studies focused on the form factors that have significant effects on the user experiences and suggest the appropriate level of form factors to deliver intended user experiences by adjusting the various shapes [13], flexibility [14], sizes [15], stucture and quantify of the surfaces [16] of the display.

These discussions show that the flex ble display's physical forms act as a point of contact to deliver the user experiences; in addition, the designers should understand how the user recognizes the display's physical form and relates it to specific user experiences. Currently, the relationship between the flexible display's forms and the user experiences are studied based on the researcher's interpretation or case studies only for certain types of experiences. A methodical and thorough study is essential for general purposes.

\section{User Survey}

In this study, a user survey was conducted to derive the relationship between the flexible display's form factors and the user experiences. By setting the flexible display's form factor values and the expected user experience types established in the previous studies as the variables, the effectiveness of the form factor values to the user experience types were examined.

\subsection{Flexible Display's Form Factors}

According to the results of the previous studies [1], flexible display's form factors can be classified as Shape, Flexibility, Size, Multi-surface, Texture, and Transparency, and their form factor values are established accordingly, as shown in Table1. These form factor values are used as independent variables in this study. 
Table 1. Flexible Display's Form Factors and Form Factor Values

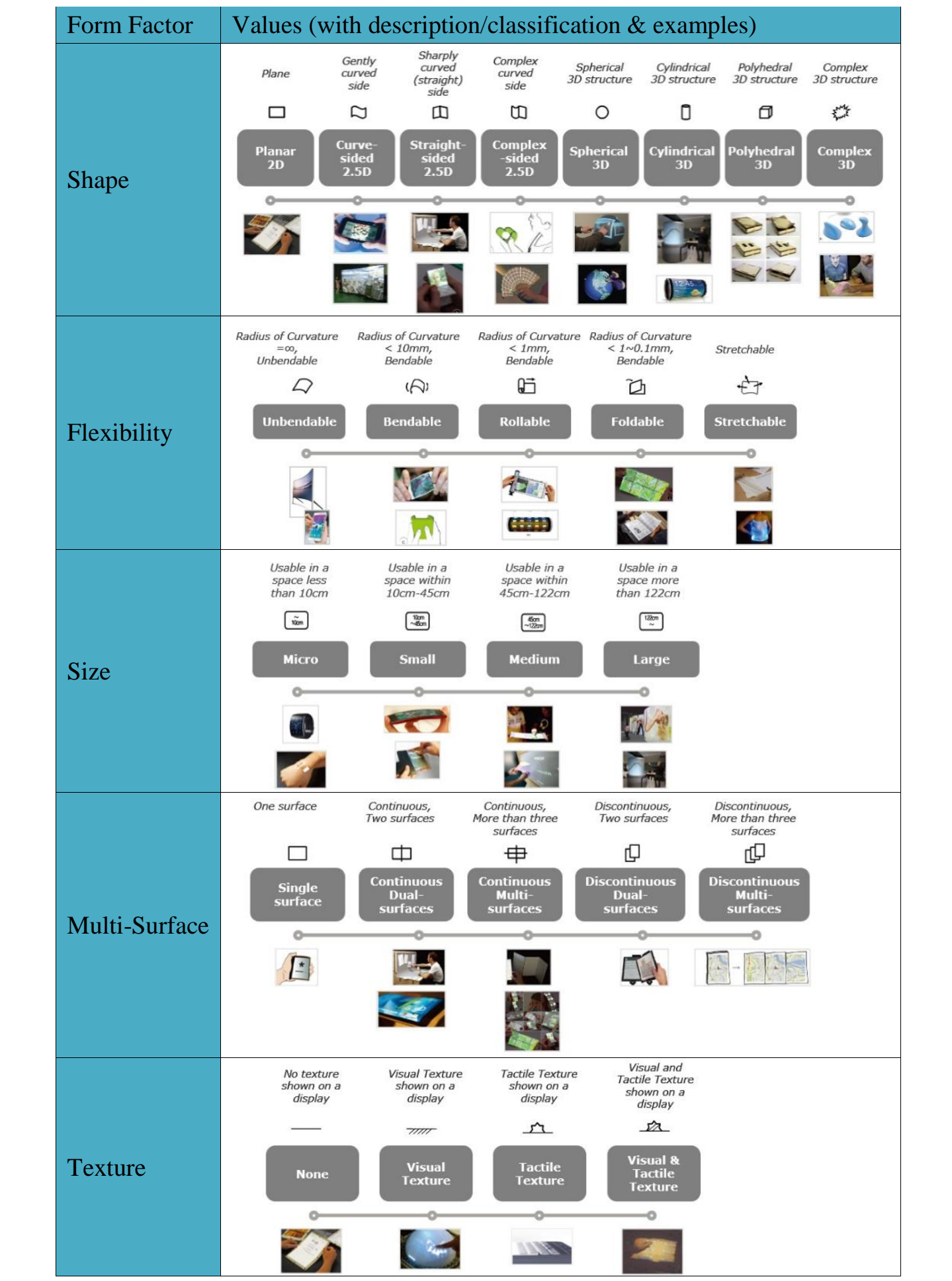




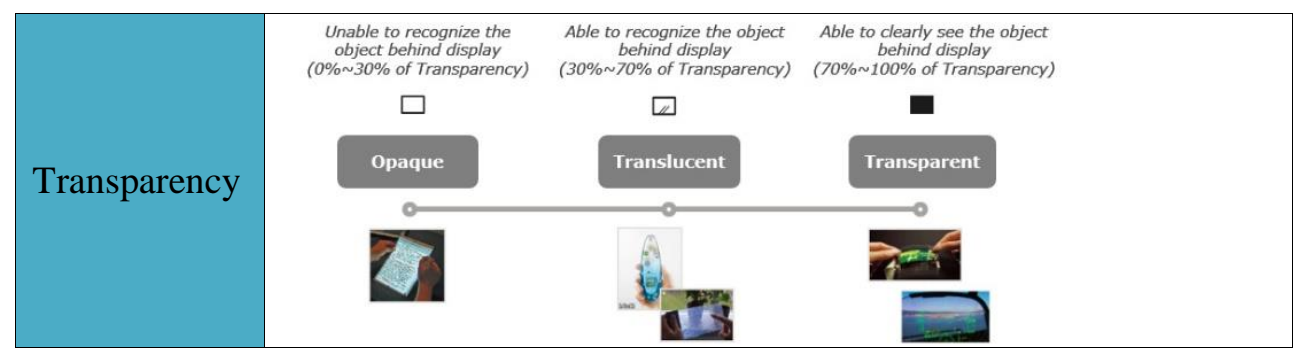

\subsection{Flexible Display's User's Expected Experience}

According to the previous studies that researched the expected user experiences from the interface that used flexible displays [4], altogether 10 types are derived: functionality, understandability, pleasure, convenience, familiarity, stimulation, adaptability, collectivity, reality, and aesthetic. Their definitions are shown in Table2. The 10 types of user experiences were used as independent variables in this study.

Table 2. 10 Types of User's Expected Experiences from Flexible Display

\begin{tabular}{|c|c|}
\hline Type & \\
\hline Functionality & $\begin{array}{l}\text { An experience where information and functions provided in the } \\
\text { flexible display interface are appropriate to its physical characteristics } \\
\text { and where it can be easily carried along and safely used due to its } \\
\text { unbreakableness }\end{array}$ \\
\hline $\begin{array}{l}\text { Understanda } \\
\text { bility }\end{array}$ & $\begin{array}{l}\text { An experience where the user can easily learn the new usage of the } \\
\text { flexible display interface and understands the usage conditions } \\
\text { correctly to ensure ts use }\end{array}$ \\
\hline Pleasure & $\begin{array}{l}\text { An experience where the user can play the flexible display interface } \\
\text { with interest and derive mentaband physical pleasure }\end{array}$ \\
\hline Convenience & $\begin{array}{l}\text { An experience where the user can easily use the flexible display } \\
\text { interface and its conditions are automatically customized and wearable } \\
\text { when applicable so that the user can use is more easily }\end{array}$ \\
\hline $\mathrm{F}$ & $\begin{array}{l}\text { An experience where the user can naturally operate the flexible display } \\
\text { interface by recognition of the past experiences or by instincts }\end{array}$ \\
\hline Stimulation & $\begin{array}{l}\text { An experience where the flexible display interface reacts to the tactile } \\
\text { action immediately and shows the user how to react naturally and } \\
\text { derive pleasure }\end{array}$ \\
\hline Adapt: & $\begin{array}{l}\text { An experience where the flexible display interface changes } \\
\text { appropriately to a certain condition or environment and allows the user } \\
\text { to solve the physical problem and maintain financial feasibility }\end{array}$ \\
\hline Collectivity & $\begin{array}{l}\text { An experience where more than two users work together and share the } \\
\text { information effectively using the flexible display interface }\end{array}$ \\
\hline Reality & $\begin{array}{l}\text { An experience by the user of psychological and perceptual reality in } \\
\text { harmony with the real environment when using the flexible display } \\
\text { interface }\end{array}$ \\
\hline Aesthetic & $\begin{array}{l}\text { An experience where the user can be emotionally satisfied due to the } \\
\text { aesthetic excellence of the flexible display interface }\end{array}$ \\
\hline
\end{tabular}




\subsection{User Survey Process and Results}

A survey to measure the user experiences by the flexible display's form factor values was conducted. The five-point Likert scale of 'Strongly Agree', 'Agree', 'Undecided', 'Disagree' and 'Strongly Disagree' was used to measure the expected user experience type according to each form factor value. To help better understanding of each form factor value, some images of the examples and the explanation of its classification criteria were presented. Each page was composed of each form factor value and the influence from the question order was eliminated by randomizing the form factors. This study was completed by a survey system on a website, and the respondents were altogether 251 with $49.8 \%$ of male and $50.2 \%$ of female. Of the participants, $37.8 \%$ were in 20 's, $40.2 \%$ were in 30 's, and $21.9 \%$ were in 40 's and above.

The survey results were used to determine differences in the user experiences according to the flexible display's form factor values by using the ANOVA (one-way analysis of variance). When there was a significant difference, the significant effectiveness of each form factor value to the user experience was analyzed by using the Univariate GLM (Univariate general linear model).The results by the user experience types were as follows.

Table 3 showed the values of $\beta$ that have significant effects in the significant value of .05 for the form factors and the values that were positive1y related with the 10 types of the experiences. The experience types were included in the Table column; E1 denoted Functionality[17], E2 Understandability, E3 Pleasure E4 Convenience, E5 Familiarity, E6 Stimulation, E7 Adaptability, E8 Collectivity, E9 Reality, and E10 Aesthetic. The form factors were included in the Table rows; $S H$ denoted Shape(Sh-1= Planar 2D, Sh-2= Curve-sided 2.5D, Sh-3 $=$ Straight-sided 25D, Sh $-4=$ Complex-sided 2.5D, Sh-5= Spherical 3D, Sh-6= Cylindrical 3D, Sh $-7=$ Polyhedral 3D, Sh-8= Complex 3D), FL Flexibility $(\mathrm{Fl}-1=$ Unbendable, Fl-2 $=$ Bendable, $\mathrm{Fl}-3=$ Rollable, Fl-4= Foldable, Fl-5= Stretchable), SI Size(Si-1= Mioro, $8 \mathrm{i} 2=$ Small, Si-3= Medium, Si-4= Large), MU MultiSurface $(\mathrm{Mu}-1=$ Single surface. $\mathrm{Mu}-2=$ Continuous Dual-surfaces, $\mathrm{Mu}-3=$ Continuous Multi-surfaces, Mu-4= Discontinuous Dual-surfaces, Mu-5= Discontinuous Multisurfaces), TE Texture(Te-1= None, Te-2= Visual Texture, Te-3= Tactile Texture, Te-4= Visual \& Tactile Texure), and TR Transparency $(\operatorname{Tr}-1=$ Opaque, Tr- $2=$ Translucent, $\mathrm{Tr}-$ $3=$ Transparent $)$

Table 3 Form Factors that Have Positive Relationship with the UX Types

\begin{tabular}{|c|c|c|c|c|c|c|c|c|c|c|c|}
\hline & \multicolumn{2}{|c|}{\begin{tabular}{l|l} 
E1 & E2
\end{tabular}} & E3 & $\mathrm{E} 4$ & E5 & E6 & \multirow{2}{*}{$\begin{array}{c}\mathrm{E} 7 \\
\beta=.156 \\
\mathrm{P}=.013 \\
\end{array}$} & \multirow{2}{*}{\begin{tabular}{c|}
$\mathrm{E} 8$ \\
$\beta=.137$ \\
$\mathrm{P}=.029$ \\
\end{tabular}} & \multirow[t]{2}{*}{ E9 } & E10 \\
\hline & Sh-1 & & $\begin{array}{l}\beta=.176 \\
P=.005\end{array}$ & & $\begin{array}{l}\beta=.212 \\
P=.001\end{array}$ & $\begin{array}{l}\beta=.325 \\
P=.000\end{array}$ & & & & & \\
\hline & Sh-2 & & & & $\begin{array}{l}\beta=.143 \\
P=.022 \\
\end{array}$ & & & & & & \\
\hline & Sn-3 & - & & & \begin{tabular}{|l}
$\beta=.143$ \\
$\mathrm{P}=.022$ \\
\end{tabular} & & & & & & \\
\hline & $\mathrm{Sh}-4$ & & & & & & & & & & \\
\hline 511 & Sh-5 & & & $\begin{array}{l}\beta=.231, \\
P=.000\end{array}$ & & & & & $\begin{array}{l}\beta=.182 \\
P=.004\end{array}$ & & $\begin{array}{l}\beta=.191 \\
P=.002\end{array}$ \\
\hline & Sh-6 & $\begin{array}{l}\beta=.161 \\
P=.011\end{array}$ & & $\begin{array}{l}\beta=.128, \\
\mathrm{P}=.041\end{array}$ & \begin{tabular}{|l|l}
$\beta=.138$ \\
$P=.027$ \\
\end{tabular} & & & & $\begin{array}{l}\beta=.159 \\
\mathrm{P}=.011\end{array}$ & & \\
\hline & Sh-7 & & & & & & & & & & \\
\hline & Sh-8 & & & $\begin{array}{l}\beta=.136, \\
P=.029\end{array}$ & & & $\begin{array}{l}\beta=.209, \\
P=.001\end{array}$ & & & & \\
\hline & Fl-1 & & & & & & & & & & \\
\hline$\Gamma L$ & Fl-2 & & & $\begin{array}{l}\beta=.137, \\
P=.029\end{array}$ & & & & & & & \\
\hline
\end{tabular}




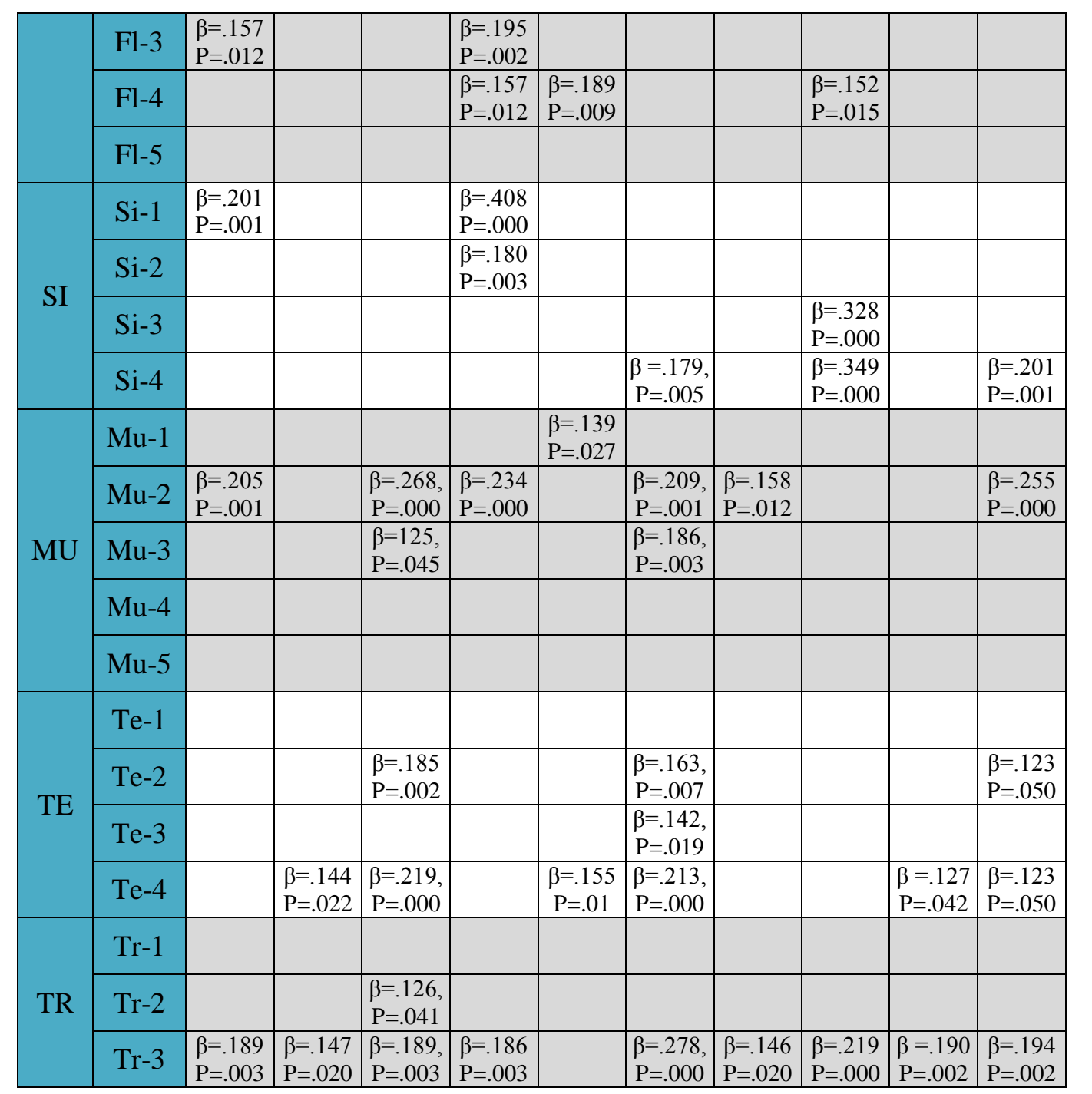

\section{Conclusion}

Welcoming the period era of a new paradigm changing change from a flat interface to an interface in various phy sical forms, this study was intended to understand the physical forms as the point of contact to deliver the meaning of the user experience and the relationship between the form factors and the user experiences of the flexible display in the aspect of the user experience designs.

The significant effectiveness of the form factor values to each user experience type was all differen on the online user survey. This indicates indicated that the designer can could utilize a certain form factor to convey a particular user experience. Also, the derived relationship in this study between the form factors and the user experiences can be provided as the an empirical index of form factors to understand the form factors and their values to be used by the designer to carry create a certain experience that meets the user is expecting expectation.

This study is aimed intended to empirically understand that the flexible display form factors affect the users' perception of the experiences in the view of according to the user experience designs, and has proposed an overall and objective study frame. 


\section{Acknowledgments}

This work was supported by Industrial Technology Innovation Program (Design Technology Innovation Program) funded by the Ministry of Trade, Industry and Energy (MOTIE, Korea). (No. 10050025)

\section{References}

[1] S. E. Chung, J. H. Noh, S. Ahn, E. S. Chu, and H. Y. Ryoo, "Form Factors of Flexible Display Interface", Journal of Korea Design Forum, vol. 48, (2015), pp. 237-250.

[2] D. Holman and R. Vertegaal, "Organic user interfaces: designing computers in any way, shape, or form", Communications of the ACM, vol. 51, no. 6, (2008), pp. 48-55.

[3] M.K. Rasmussen, E.W. Pedersen, M.G. Petersen, and K. Hornbæk, "Shape-changing interfaces: a review of the design space and open research questions", Proceedings of the SIGCHI Conference on Human Factors in Computing Systems, (2012), pp.735-344

[4] S. E. Chung, Y. S. Yoon, R. Lee, Y. S. Lim, H. J. Choi, and H. Y. Ryoo, "User Expectation Experience of Flexible Display Interface”, Design Convergence Study, vol. 15, no. 2, (2016), pp. 301-317

[5] R. Vertegaal and I. Poupyrev, "Organic User Interfaces", Communications of the ACM, vol 51, no. 6, (2008), pp. 26-30

[6] M. Weiss, S. Voelker, C. Sutter, and J. Borchers, "BendDesk: dragging across the curve", Proceedings of the ACM International Conference on Interactive Tabletops and Sur acess, (2010).

[7] G. Beyer, F. Alt, J. Müller, A. Schmidt, K. Isakovic, S. Klose, and I. Haulsen, Aurdience behavior around large interactive cylindrical screens", Proceedings of the SIGCHI Conference on Human Factors in Computing Systems, (2011), pp. 1021-1030

[8] H. Benko, A. D. Wilson, and R. Balakrishnan, "Sphere: multi-touch interactions on a spherical display", Proceedings of the 21st annual ACM symposium on User interface software and technology, (2008), pp.77-86

[9] M. Khalilbeigi, R. Lissermann, M. Mühlhäuser, and J. Steimle, Xpaaand: interaction techniques for rollable displays", Proceedings of the SIGCHI Conference on Human Factors in Computing Systems, (2011), pp.2729-2732

[10] Y. Kinoshita, K. Go, R. Kozono, and K. Kaneko, "Origami tessellation display: interaction techniques using origami-based deformable surfaces", Proceedings of the extended abstracts of the 32nd annual ACM conference on Human factors incomputing systems, (2014), pp.1837-1842

[11] J.C. Lee, S.E. Hudson, and E. Tse "Foldable interactive displays", Proceedings of the The 21st annual ACM symposium on User interface softwate and technology, (2008), pp. 287-290

[12] E. Tjalve, "A Short Course in Industrial Désign", Newness-Butterworths, London; Boston, (1979).

[13] F. Teubl, C. Kurashima, M. Cabral, and M. A. Zuffo, "Small-scale and flexible platform for multiprojector systems development", Proceedings of Virtual and Augmented Reality (SVR), 2013 XV Symposium on (2013), pp. 216-219.

[14] S. S. Lee, S. Kim, B. Jin, E. Cho, B. Kim, X. Jia, and K. P. Lee, "How users manipulate deformable displays as input devices" Proceedings of the SIGCHI Conference on Human Factors in Computing Systems, (2010), pp. 1647-1656.

[15] S. Lee, Y. Lim, and K. Lee; "Exploring the effects of size on deformable user interfaces", Proceedings of the 14th internalional conference on Human-computer interaction with mobile devices and services companion, (2012). pp. 89-94.

[16] M. Khalilbeigi, R. Lissermann, W. Kleine, and J. Steimle, "FoldMe: interacting with double-sided foldable displays", Proceedings of the Sixth International Conference on Tangible, Embedded and Embodied Interaction, (2012), pp. 33-40.

[17] S. E.Chung and H. Y. Ryoo, "An Investigation on the Effect of Flexible Display's Form Factors toward Functionality User Experience", Proceedings of International Workshop Mechanical Engineering, (2016), pp. 109-113. 


\section{Authors}

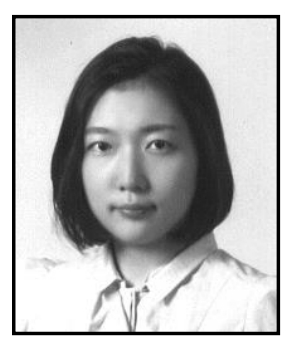

Seung Eun Chung, is a Ph.D. candidate of Division of Digital media in Ewha Womans University. Her research areas are user experience design, graphic user interface design, and so on.

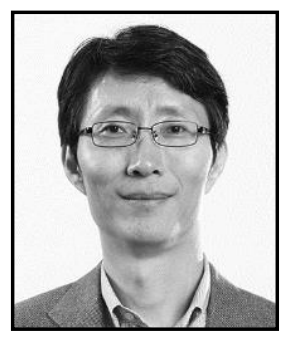

Han Young Ryoo, is a professor in the Division of Digital media at Ewha Womans University. He received B.S. \& M.F.A. degrees in Industrial Design from KAIST (Korea Advanced Institute of Science and Technology) \& Kookmin University respectively, and D. Sc. in Interactive Multimedia from the Department of Computer Science at George Washington University. He has also worked as an editor of Journal of the HCI Society of Korea. His resea ch/areas are user experience design, user interface design, usability evaluation, and so on.

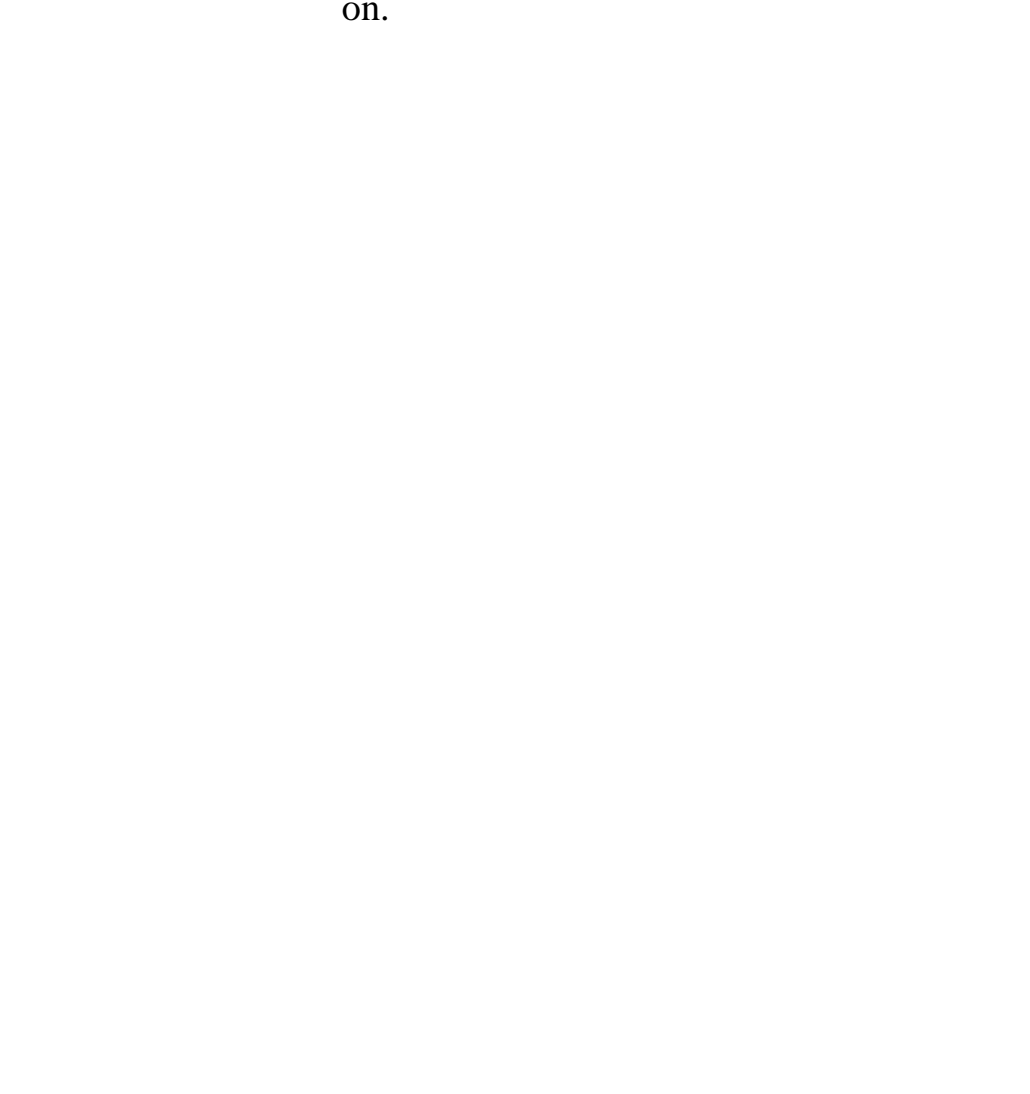

